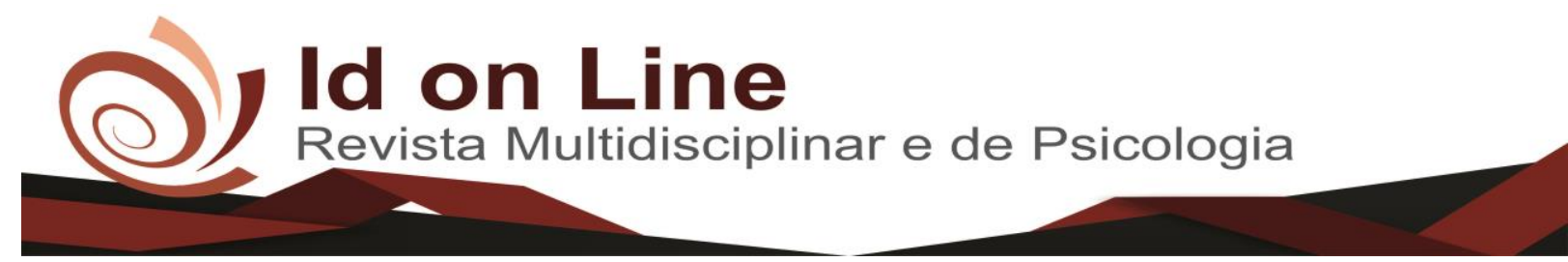

Artigo

\title{
Febre Amarela: Sua Perspectiva No Brasil
}

\author{
Raissa de Moura Costa ${ }^{1}$, Larissa de Souza Facioli ${ }^{2}$, Thainá Desiree Franco dos Reis ${ }^{3}$, \\ Odila Rigolin de $\mathrm{Sa}^{4}$, Nicole Blanco Bernardes ${ }^{5}$
}

\begin{abstract}
Resumo: Em pleno século XVII, ocorreu o primeiro surto de febre amarela em terras brasileiras, mais especificamente no nordeste. Ao passar dos anos, com a expansão territorial, a doença se alastrou para outras localidades, gerando novos casos epidemiológicos e tornando-se assim uma doença reemergente. Portanto, objetivo deste trabalho é discutir as características da febre amarela, tais como sua letalidade, epidemiologia, tratamento e diagnóstico e também sua gravidade juntamente com a importância da prevenção no Brasil. As buscas foram realizadas em duas bases de dados bibliográficos, sendo estes SciELO (Scientific Eletronic Libray Online) e Google Acadêmico. Foram selecionados artigos do período de 1976 a 2017. A febre amarela possui origens históricas, sendo trazida dos navios negreiros na época da colonização. Essa doença possui ciclo urbano e silvestre, apresentando os vetores. Atualmente, a doença ocorre em ciclos de seis a sete anos, sendo classificada como reemergente, em áreas de zona rural e nos principais estados de Minas Gerais e São Paulo. Fica claro, portanto, que a febre amarela é uma doença que se proliferou devido ao avanço da urbanização e da ineficácia de políticas públicas para erradicá-la. Logo a melhor forma para proteção é a conscientização da população e a preservação ambiental.
\end{abstract}

Palavras-chave: Febre amarela, Culex quinquefasciatus, Aedes aegypti, Haemagogus.

\section{Yellow Fever: Its Perspective In Brazil}

\begin{abstract}
In the 17th century, the first outbreak of yellow fever occurred in Brazilian lands, more specifically in the northeast. Over the years, with a territorial expansion, a disease has spread to other locations, generating new epidemiological examples and thus becoming a reemerging disease. Thus, epidemiology, treatment and disease and their identification, along with their importance, in Brazil. As searches were done in two bibliographic databases, these being the SciELO and Google Scholar. Articles from the period 1976 to 2017 were closed. Yellow fever has historical origins, being brought from the slave ships at the time of colonization. This is the proof of the urban and wild cycle, presenting the vectors. Currently, the disease occurs in seven-year cycles, being classified as reemergent, in rural areas and in the main states of Minas Gerais and São Paulo. It is clear, therefore, that the yellow fever is a disease that is proliferated by the advance of the urbanization and the inefficacy of the public data to eradicate it. As soon as protection is an awareness of the population and an environmental preservation.
\end{abstract}

Keywords: Yellow fever, Culex quinquefasciatus, Aedes aegypti, Haemagogus.

\footnotetext{
${ }^{1}$ Graduanda em Biomedicina - UEMG. Unidade acadêmica de Passos. Contato: moura_raissa@ hotmail.com;

${ }^{2}$ Graduanda em Biomedicina - UEMG. Unidade acadêmica de Passos. Contato: larissafacioli@ gmail.com;

${ }^{3}$ Graduada em Ciências Biológicas (Bacharelado) pela Universidade do Estado de Minas Gerais - Unidade Passos. Laboratório de Hidrobiologia e LAAPA. Contato: thainadfr@gmail.com;

${ }^{4}$ Doutora em Ecologia e Recursos naturais pela Universidade Federal de São Carlos, mestre em Ciências da Engenharia Ambiental pela Universidade de São Paulo Docente nível VI dos cursos de Ciências Biológicas Licenciatura e Bacharelado e Medicina, UEMG Unidade acadêmica de Passos - MG. Contato: odilarigolin@yahoo.com.br;

${ }^{5}$ Graduação em Ciências Biológicas pelo Centro Universitário Barão de Mauá. Mestranda em Ciências da saúde (USP). Docente da Universidade Estadual de Minas gerais. Contato: nicoleblanco100@yahoo.com.
} 


\section{Introdução}

No contexto histórico da colonização, houve a necessidade de importação de escravos africanos para a exploração da terra brasileira, principalmente nas plantações de grandes senhores (FRANCO, 1976). Naquele período, os escravos eram transportados em navios com condições precárias e logo se notava a proliferação de doenças incomuns no Brasil por conta dos insetos e ratos que ali existiam, a exemplo: leptospirose, escorbuto, hepatite $\mathrm{B}$, lepra e febre amarela. Algumas prevaleceram e se tornaram grandes epidemias que causaram elevados índices de mortalidade da população, gerando uma preocupação com a saúde pública de modo a iniciarem tentativas de controle (SENISE e SENISE, 2011).

Em meados do século XVII, veio à tona o primeiro surto de febre amarela no Brasil, na região nordeste, que levou cerca de 10 anos para ser amenizada. Ao longo dos anos, com o processo de expansão territorial, a doença se alastrou para outras localidades, gerando novos casos epidemiológicos e tornando-se assim uma doença reemergente (SAAD e BARATA, 2016).

O desconhecimento do agente causador da febre amarela dificultava o tratamento e sua erradicação, por não saberem como preveni-la. A partir do pouco avanço tecnológico da época, Juan Carlos Finlay, médico e cientista cubano, conseguiu identificar o agente causador e com isso surgiram métodos de prevenção contra novos casos, dando início a uma nova era na saúde. Porém, no século XXI, mesmo com todos os recursos desenvolvidos, novos focos de febre amarela foram registrados (ANDRADE,1976). Diante disso, o objetivo do trabalho é discutir as características da febre amarela, tais como sua letalidade, epidemiologia, tratamento e diagnóstico e também sua gravidade juntamente com a importância da prevenção no Brasil.

\section{Metodologia}

As buscas foram realizadas em duas bases de dados bibliográficos, sendo estes SciELO (Scientific Eletronic Libray Online) e Google Acadêmico. Foram selecionados artigos do período de 1976 a 2017, uma vez que esse trabalho lucidou o contexto histórico da febre 
amarela, a linguagem adotada para tal pesquisa foi o português. Nas buscas foram utilizados os seguintes termos: febre amarela, Oswaldo Cruz, epidemia, Juan Carlos Finlay, Culex quinquefasciatus, Aedes aegypti, Haemagogus, vírus, vetor, febre amarela urbana, febre amarela silvestre, vacina, sintomas e profilaxia. No total foram utilizadas vinte e oito referências, dessas dezenove são artigos, quatro livros, duas revistas e três sites.

\section{Contexto histórico}

A febre amarela existe a cerca de trezentos e sessenta e nove anos no mundo, sendo seu primeiro relato identificado na população maia, no México na ilha de Yucatán em 1648. Ela também se manifestou na Europa por volta de 1700, mas foi em 1730 que ocorreu a primeira epidemia causando aproximadamente dois mil e duzentos óbitos. Além disso, nos Estados Unidos os séculos XVIII e XIX foram marcados por diversos casos da doença (MINISTÉRIO DA SAÚDE, 2017).

No Brasil, essa patologia possui raízes históricas tendo em torno de trezentos anos de repercussão no país, sendo uma doença de origem africana foi trazida na época da colonização pelos navios negreiros. Diante disso, no ato do transporte as condições vividas por esses tripulantes eram extremamente precárias, principalmente no quesito higiene, pois ficavam semanas sem tomar banho, além do acúmulo de resíduos alimentícios o que favoreceu a proliferação de muitos micro-organismos contribuindo para propagação de doenças. Ademais, muitos escravos já embarcavam doentes porque a maioria deles eram prisioneiros de guerra e já viviam em condições desumanas favorecendo assim as manifestações de mazelas, logo era comum que esses escravos transmitissem doenças, desconhecidas pelo homem, para o europeu e este para os índios brasileiros (COSTA, 2011).

O primeiro caso epidêmico no território brasileiro ocorreu em 1685 em Recife, atual capital de Pernambuco, onde acarretou mortes por um período de dez anos, apresentando uma frequência intervalada. No ano de 1692 atingiu a Bahia causando morte de novecentas pessoas. Nesse período, o conhecimento sobre micro-organismos foi desenvolvido por Luís Pasteur e desse modo, suas pesquisas influenciaram os médicos da época a concluírem que a enfermidade era causada por bactérias, e também que o contágio era por contato físico e não por sangue, por via de um vetor como posterirormente foi descoberto (BENCHIMOL, 1994). 
O grande defensor de que ela não era uma doença contagiosa foi Juan Carlos Finlay, médico e cientista, que começou a observar em Havana, ilha de Cuba, que era necessário um doente, e um agente etiológico para transmissão da febre amarela, mas essas ideias não foram aceitas. O que ajudou Finlay a provar sua teoria foi a descoberta em 1878 de que um mosquito era responsável por causar a filariose humana. Seus experimentos consistiam no teste de duas espécies, Culex quinquefasciatus e Stegomia fasciata, que eram comuns a todos os lugares onde tinham relato de febre amarela e conseguiu a comprovação científica desse fato. Porém, só em 1900, quando os Estados Unidos refizeram os experimentos que a teoria de Finlay foi aceita, todavia os transmissores estavam incorretos, comprovando que o verdadeiro vetor era o Aedes aegypti, o que levou a criação de medidas profiláticas (CONSOLI, 2016).

No Brasil não foi muito diferente, já que Emilio Ribas, um médico brasileiro de destaque, lançou a primeira campanha de combate ao mosquito no estado de São Paulo em 1904. Ele atuou no Instituto Sanitário durante vinte anos e nesse período exterminou inúmeras quantidades de viveiros do mosquito transmissor da febre amarela juntamente com Oswaldo Cruz, pioneiro na medicina preventiva e curativa no país e diretor técnico do Instituto Butantã (REZENDE, 2009).

Oswaldo Cruz enfrentou uma época de péssimas condições para a população, além da chegada de imigrantes e da ausência de recursos para pesquisas científicas, o que agravava as manifestações da doença. Por demonstrar uma grande dedicação foi nomeado diretor geral do Instituto Butantã e logo em seguida começou a realizar as medidas profiláticas para o controle da enfermidade. Entretanto suas medidas foram consideradas abusivas para época, pois ele obrigava a vacinação sem o devido conhecimento do propósito da vacina por meio da invasão das moradias. Além disso, era obrigatório a notificação de casos suspeitos da doença sendo a primeira enfermidade a ter esse tipo de medida no Brasil. Todavia a população inicialmente desconhecia a situação gerando muita discórdia, o que acarretou a conhecida revolta da vacina. A imprensa divulgava que essa ação era desnecessária, deixando o trabalho de Cruz ainda mais árduo, porém ele provou que estava certo controlando a doença. Só tempos depois, foi criado o "Conselho do Povo" para orientar e esclarecer as causas e como evitar a doença. Em 1907 ele foi premiado com a medalha de ouro no Décimo Quarto Congresso Internacional de Higiene e Demografia de Berlim pela erradicação da febre amarela (NOBRE,1994).

\section{Epidemiologia}


O mosquito Aedes aegypti (Figura 1) tem origem Egípcia e sua dispersão se deu em consequência das navegações históricas, primeiramente da costa leste do continente africano para as Américas e posteriormente da costa oeste da África para o continente asiático. Em 1762, era descrito cientificamente como Culex aegypti (mosquito egípcio), porém, notou-se que a espécie A.aegypti apresentava características morfológicas e biológicas semelhantes as de outras espécies do gênero Aedes, que foi descrito em 1818. Ele é menor em relação aos outros, se caracteriza por ser preto com listas brancas, suas asas são translúcidas e é inaudível ao ser humano. Caso a fêmea já esteja contaminada, seus descendentes nascerão portadores do vírus (FORATTINI, 2002).

Conhecido popularmente como "pernilongo-rajado", o mosquito é predominante nas regiões tropicais e subtropicais, não sobrevivendo a temperaturas muito baixas, e é caracterizado por seus hábitos cinantrópicos e antropogênicos, pois ele depende tanto de ambientes propícios para criadouros que o meio de vida urbano oferece, quanto do sangue humano, que é preferível para o amadurecimento dos ovos por suas quantidades de proteínas. Apenas as fêmeas alimenta-se do sangue, os machos alimentam-se exclusivamente de frutas, e uma fêmea pode pôr entre 150 e 200 ovos por vez, podendo chegar a 1500 ovos durante toda sua fase adulta, que dura em média 30 dias (SESA-ES, 2017).

Os ovos possuem um formato alongado e uma coloração negro brilhante. São postos em paredes de recipientes com água, milimétricamente acima do nível, ou em ocos de árvores, podendo resistir mais de 400 dias à seca. Quando chove, o nível de água encobre os ovos que eclodem em menos de trinta minutos e passam por 4 fases de mudança da larva (ovo, larva, pupa e adultos) e em aproximadamente 9 dias se tem novos mosquitos (SUVISA-GO, 2017).

A febre amarela silvestre tem como ciclo principal os macacos brasileiros e o mosquito pertencente ao gênero Haemagogus (Figura 1). O macaco, como hospedeiro, desempenha dupla função, a de amplificador e a de disseminador do vírus. O mosquito, no entanto, é considerado vetor reservatório do vírus e responsável por sua dispersão. Esta dispersão é facilitada em grandes centros urbanos onde não há vacinação e nem medidas de prevenção. A contaminação do homem ocorre por meio do contato com os mosquitos do gênero Haemagogus em áreas epidêmicas pontuais (VASCONCELOS, 2003).

Para o controle da dispersão é necessário que a população que penetre ou resida nos arredores desses locais se vacinem e tomem os devidos cuidados para que não facilite a reprodução do mosquito (HERVÉ et al., 1985). 


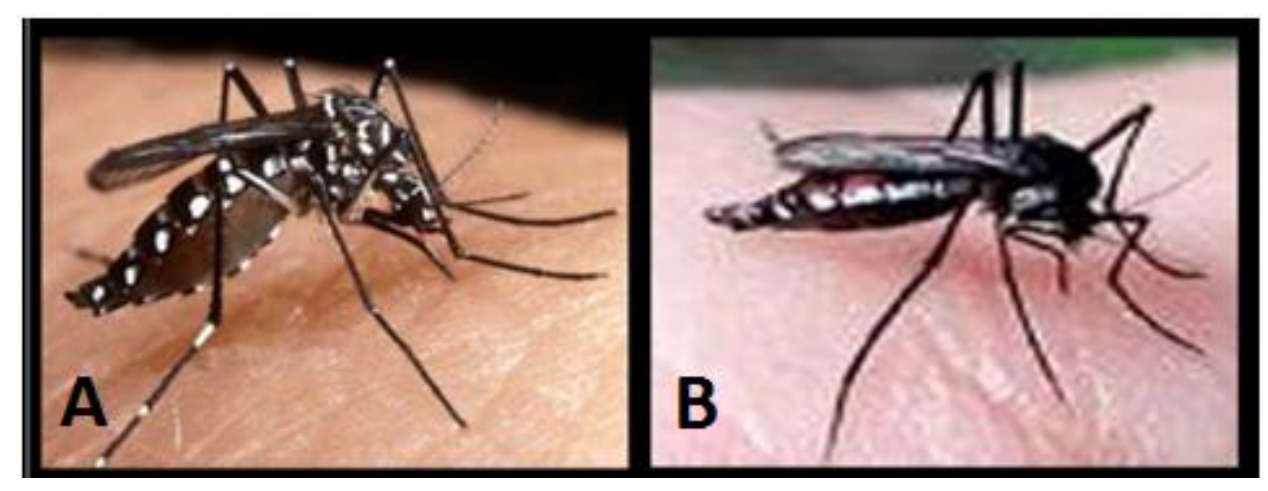

Figura 1. Diferença entre os vetores Aedes aegypti (A) e Haemagogus (B).

\section{Vírus}

O vírus da febre amarela é classificado como ribovírus, pois seu ácido nucléico é formado pelo RNA. Eles são constituídos por uma capa proteica chamada capsídeo que envolve o ácido nucleico, esse conjunto denomina-se núcleo capsídeo (BESERRAL et al., 2009).

Para se reproduzirem, o vírus necessita de um metabolismo celular, podendo ocorrer de duas formas: invadindo com capsídeo ou introduzindo apenas seu material genético no interior das células. Esse processo tem início quando o vírus se liga à parede celular ou a membrana da célula e a partir do momento que está em seu interior o vírus controla o seu metabolismo e utiliza suas substâncias existentes a fim de multiplicar seu próprio material genético (LEMOS, 2015).

\section{Ciclo biológico do Vetor}

A febre amarela na África se caracteriza por apenas um ciclo de transmissão, o ciclo silvestre (Figura 2), que tem como hospedeiro definitivo o macaco e se define por transmitir o vírus do macaco para outros primatas, podendo ser humanos ou não. A infecção nos humanos se dá caso ele invada o habitat dos transmissores ou haja uma migração dos vetores. No ciclo africano, estão envolvidos os mosquitos do gênero Aedes sendo as espécies A. africanus, A.simpsoni, A. furcifer, A. luteocephalus e A. taylori (WERMELINGER E CARVALHO, 2016). 
Já no continente americano, a transmissão se dá tanto por ciclo silvestre quanto por ciclo urbano. No ciclo silvestre estão envolvidos os mosquitos do gênero Haemagogus e Sabethes, tendo como hospedeiro definitivo os macacos dos gêneros Allouata, Cebus, Atelles e Callithrix. No ciclo urbano o principal vetor do vírus é o mosquito Aedes aegypti, e o ciclo se caracteriza pela transmissão do vírus de homem para homens (CAVALCANTE, et al., 2014).

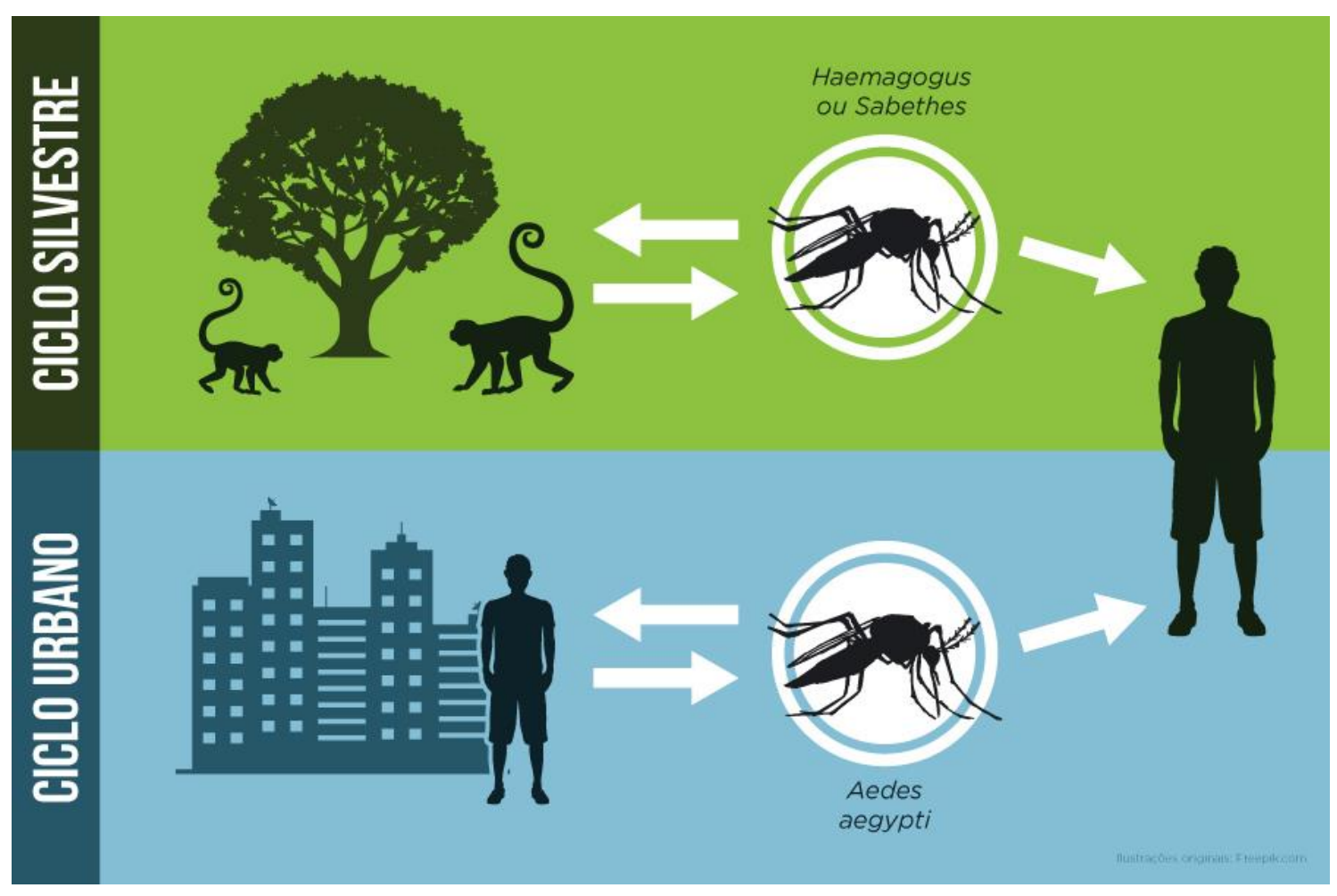

Figura 2. Ciclo biológico urbano (do mosquito Aedes aegypti) e silvestre (do mosquito Haemagogus).

\section{Vacina}

A preocupação com as doenças causadas por vírus datam de muitos anos, assim foi-se necessário a criação de um método eficiente que atingisse apenas células infectadas por tais vírus. Desse modo, o inglês Edward Jenner em 1799 desenvolveu a primeira vacina contra a cowpox, uma doença semelhante a varíola. Logo, seus estudos serviram de base ao combate a diversas enfermidades causadas pelos vírus (SINGER et al., 1988).

Em 1936, Max Theiler e Henry Smith, da Fundação Rockefeller, organização responsável pelo estudo da febre amarela, desenvolveram a cepa 17D que é o vírus atenuado 
dessa doença e foi inicialmente testada em ratos e embriões de galinha. No ano seguinte a vacina já estava sendo testada no território brasileiro, em um campo de estudo na região de Minas Gerais e teve como resultado a imunização de mais de cinco mil pessoas. (BENCHIMOL, 2001).

A vacina da febre amarela é a primeira a apresentar o vírus atenuado da doença sendo feita em um sistema lotes-semente, ou seja, os lotes originais são introduzidos em ovos embrionários que servem de fonte para a produção do imunizante. Além disso a vacina é altamente imunogênica, isto é, confere imunidade em 95 a 99\% dos vacinados sendo bem tolerada com poucos efeitos colaterais, como por exemplo febre, mialgia e cefaleia com duração de um a dois dias. Desse modo apresenta algumas orientações para a vacinação como retrata a tabela 1 (FRAGA, 1930).

Tabela 1. Orientações para vacinação contra Febre Amarela

\begin{tabular}{|c|c|}
\hline Indicação & Esquema \\
\hline 6 a 9 meses de idade incompletos & $\begin{array}{l}\text { A vacina está indicada somente em situações de } \\
\text { emergência epidemiológicas ou viagem para } \\
\text { área de risco. }\end{array}$ \\
\hline 9 meses até antes de completar 5 anos & $\begin{array}{l}\text { Uma dose aos } 9 \text { meses de idade } \\
\text { Uma dose de reforço aos } 4 \text { anos de idade } \\
\text { Obs: Se a criança não foi vacinada aos } 9 \text { meses, } \\
\text { deve tomar a vacina e o reforço, com intervalo } \\
\text { mínimo de trinta dias entre as doses. }\end{array}$ \\
\hline \multicolumn{2}{|l|}{ Pessoas a partir dos 5 anos } \\
\hline Que receberam a dose única da vacina & $\begin{array}{l}\text { Estão imunizadas e não precisam mais se } \\
\text { vacinar. }\end{array}$ \\
\hline $\begin{array}{l}\text { Que nunca foram vacinadas ou sem } \\
\text { comprovante de vacinação }\end{array}$ & Administrar a dose única da vacina. \\
\hline $\begin{array}{l}60 \text { anos ou mais (nunca vacinada ou sem } \\
\text { comprovante de vacinação) }\end{array}$ & Apenas após avaliação médica. \\
\hline Gestantes & $\begin{array}{l}\text { A vacinação é contra indicada. Na } \\
\text { impossibilidade de adiar a vacinação, como em } \\
\text { situações de emergência epidemiológica ou } \\
\text { viagens para área de risco de contrair a doença, o } \\
\text { médico deverá avaliar o benefício/risco de } \\
\text { vacinação. }\end{array}$ \\
\hline $\begin{array}{l}\text { Lactantes de crianças com até } 6 \text { meses de } \\
\text { idade }\end{array}$ & $\begin{array}{l}\text { A vacinação é contra indicada até a criança } \\
\text { completar } 6 \text { meses de idade. Caso tenham } \\
\text { recebido a vacina, o aleitamento materno deve } \\
\text { ser suspenso por } 28 \text { dias após a vacina. }\end{array}$ \\
\hline Viajantes & $\begin{array}{l}\text { Viagens internacionais: seguir as recomendações } \\
\text { do Regulamento Sanitário Internacional } \\
\text { Viagens para áreas com recomendação de vacina } \\
\text { no Brasil: vacinar pelo menos } 10 \text { dias antes da } \\
\text { viagem. }\end{array}$ \\
\hline
\end{tabular}




\section{Sintomas}

A febre amarela é uma doença infecciosa febril aguda, de curta duração (no máximo 10 dias), de gravidade variável causada por um arbovírus (vírus transmitido por artrópodes) (BRASIL, 2010).

A vacinação é a melhor forma de se evitar e combater a febre amarela, ela deve ser aplicada 10 dias antes caso a pessoa queira viajar para lugares de risco. A vacina fica disponível em todos os postos de saúde e não há taxa alguma para quem deseja tomá-la. Ela é contra indicada para gestantes, crianças menores de 9 meses, idosos, imunodeprimidos (sistema imunológico debilitado) e pessoas alérgicas a proteína do ovo (SILVA, 1930).

É importante que as pessoas que se encontram em área de risco em determinados Estados e regiões, como a zona rural da Região Norte, Centro Oeste, estado do Maranhão, Partes dos estados do Piauí, Bahia, Minas Gerais, São Paulo, Paraná, Santa Catarina e Rio grande do Sul estejam sempre vacinados. (NOBRE et al., 1994).

A febre amarela pode provocar dores locais como no abdômen, nas costas ou nos músculos, náusea ou vômito afetando o aparelho gastrointestinal, pelo corpo pode acarretar calafrios, fadiga, febre, mal estar ou perda de apetite e também é comum confusão mental, dor de cabeça, hemorragia (gengiva, nariz, estomago, intestino e urina) e icterícia (a pele e os olhos ficam amarelos) (Figura 3) (VASCONCELO, 2002).

O tratamento da febre amarela não possui nada específico, sob hospitalização há o monitoramento de fluidos por meio da ingestão de mais líquidos ou da aplicação da terapia intravenosa, caso precise há reposição das perdas sanguíneas e o acompanhamento dos sintomas para evitar maiores complicações da doença já que esta pode apresentar casos moderados que são caracterizados por provocarem febre, dor de cabeça, náuseas e vômitos, ou casos graves que podem gerar problemas cardíacos, renais e hepáticos fatais. Caso o paciente não receba assistência médica ele pode chegar a óbito (BRASIL, 2010). 


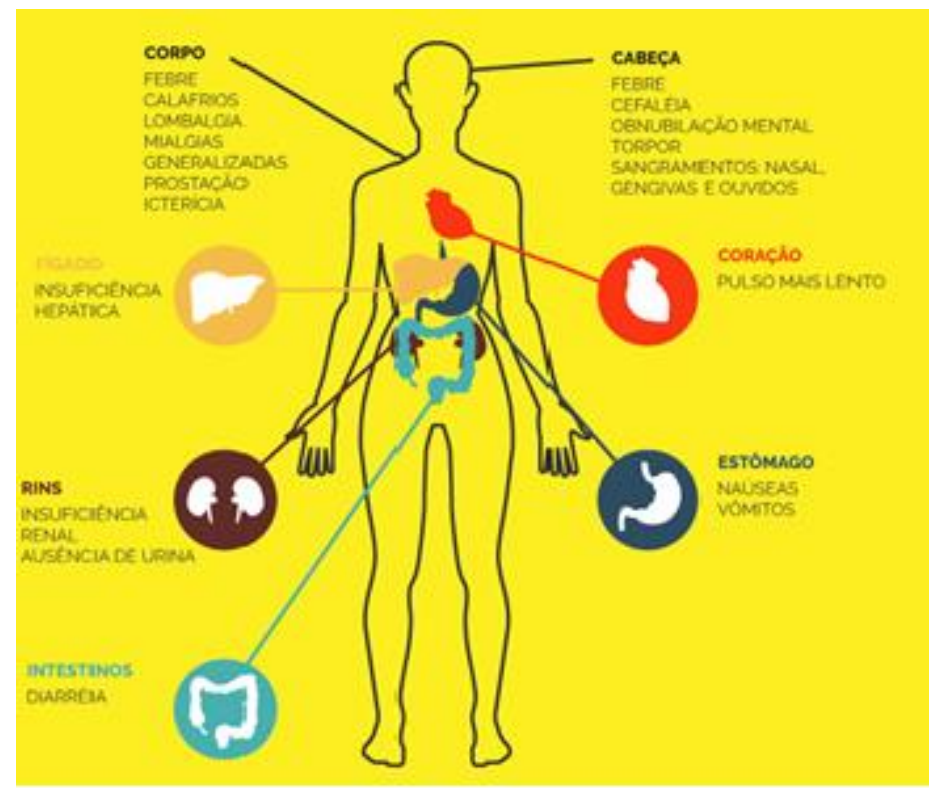

Figura 3. Quadro sintomático da Febre Amarela

\section{Medidas Profiláticas}

As medidas para o controle de doenças que são oriundas de vetores, principalmente os mosquitos, sempre foram um grande desafio para o país. Desse modo, aspectos como a infraestrutura precária, a insuficiência na coleta de lixo e a contaminação das águas comprometem a efetividade dos métodos profiláticos (ZARA et al., 2016).

Diante da necessidade de reduzir e extinguir as doenças causadas pelo Aedes aegypti é possível utilizar três tipos de mecanismos, sendo eles:

- Controle mecânico: consiste no combate ao vetor por meio da eliminação dos criadouros do mosquito, na filtragem de reservatórios de água e da instalação de telas em janelas (Figura 4).

- Controle biológico: consiste na utilização de predadores naturais ao mosquito, como peixes e sapos, que se alimentam tanto das larvas como dos adultos, usar patógenos que prejudiquem o desenvolvimento das larvas, como bactérias, fungos e parasitas que liberam toxinas larvicidas.

- Controle químico: consiste no uso de produtos químicos que mantém diretamente o vetor, como os inseticidas e também o uso de repelentes principalmente pelo grupo de risco. Além disso, outras formas de prevenção são: 
- Implantar vigilância sindrômica (que realiza exames nos quadros infecciosos agudos) em maior números de estados para tornar a vigilância epidemiológica mais sensível.

- Educar e qualificar os profissionais da saúde para aumentar o conhecimento, sua disseminação e controle das epidemias.

- Notificação de casos humanos, epizootias e de achados do vírus em vetor silvestre.

- Controle do Aedes aegypiti, por meio da redução do desmatamento, para eliminação do risco de reurbanização (ROMANO et al., 2011).

É importante ressaltar que qualquer meio de controle do vetor deve ser utilizado de forma consciente e segura, pois estando em um ecossistema existe a interdependência das espécies e é necessário cautela com o uso desse métodos para não afetar o modo de vida de outros indivíduos. E que a vacina é a principal forma de prevenção da doença (VASCONCELOS, 2010).

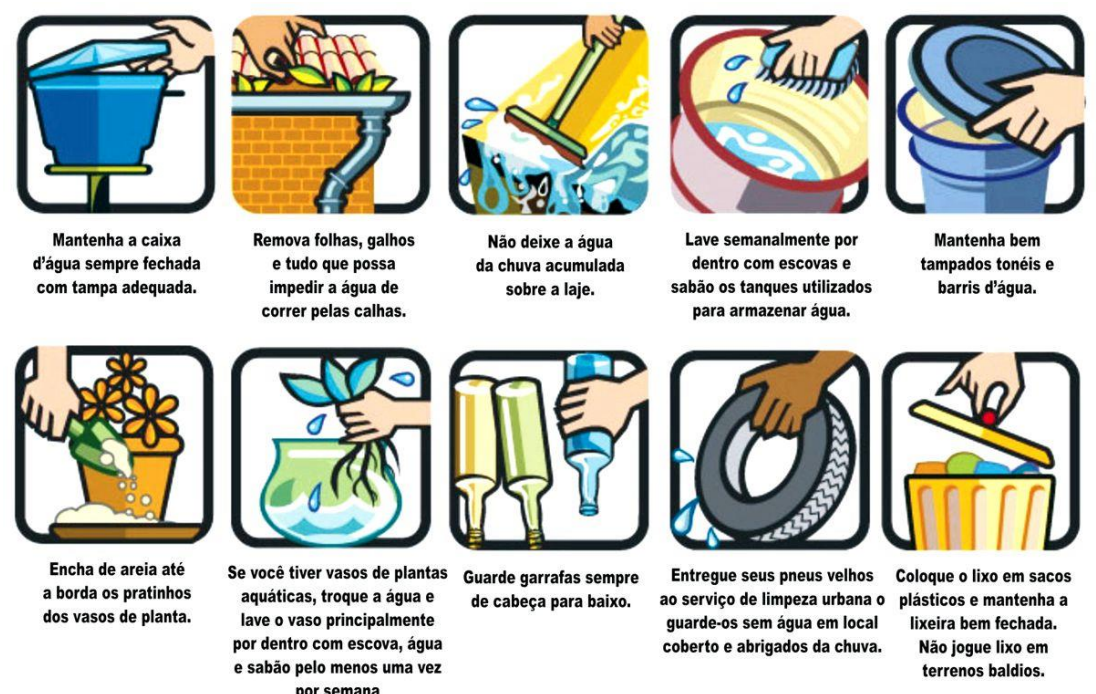

Figura 4. Principais formas de controle mecânico ao vetor da febre amarela.

- Após a vacinação são raros efeitos colaterais, podendo haver reação local da injeção, febre e mal estar. Também é recomendado aguardar no mínimo quatro semanas após a vacinação para doar sangue ou órgãos. 
- A vacina possui o vírus atenuado da doença e por isso não é recomendado a vacinação de idosos, gestantes, pessoas que estão com baixa imunidade, mulheres em período de amamentação e bebês menores de nove meses. Porém esses grupos podem ser vacinados, com orientação médica, caso residam em área de risco.

- O Brasil é o terceiro país que mais notifica casos de febre amarela na América e em todos os anos nos estados de Minas Gerais, Pará e Goiás são registradas manifestações da doença.

- $80 \%$ dos casos ocorrem com indivíduos do sexo masculino, devido a pratica de técnica agropecuárias e extração de madeira em áreas afetadas sem vacinação prévia.

- A ingestão de vitaminas do complexo B em excesso exala um cheiro na pele que funciona como repelente "natural". No entanto muitos médicos advertem que não é valido sobrecarregar o organismo com excesso de vitaminas, já que há repelentes específicos e mais eficientes no mercado farmacêutico (MINISTÉRIO DA SAÚDE, 2017).

\section{Conclusão}

Conforme apresentado no trabalho, a febre amarela possui origens históricas, sendo trazida dos navios negreiros na época da colonização. Essa doença possui ciclo urbano e silvestre, apresentando os vetores Aedes aegypti e Culex quinquefasciatus, respectivamente. Assim sua proliferação foi facilitada pelo processo de urbanização, juntamente com o desmatamento e com as péssimas condições sanitárias. Atualmente, a doença ocorre em ciclos de seis a sete anos, sendo classificada como reemergente, em áreas de zona rural e nos principais estados de Minas Gerais e São Paulo. Além disso, a melhor maneira de prevenir a doença é pela vacinação, no entanto, ainda há o medo de realizá-la devido aos possíveis efeitos colaterais. Fica claro, portanto, que a febre amarela é uma doença que se proliferou devido ao avanço da urbanização e da ineficácia de políticas públicas para erradicá-la. Logo a melhor forma para proteção é a conscientização da população e a preservação ambiental. 


\section{Referências}

ANDRADE GO. 1976. Origem da Febre Amarela na América do Sul. Ci. \& Tróp. pp. 189-202.

BARATA RB, SAAD LDC. 02 de Março de 2016. Surtos de Febre Amarela no estado de São Paulo 2000-2010. n.3. Epidemiol. Serv. Saúdel. 25: 1-92

BENCHIMOL JL. 2001. Febre amarela: a doença e a vacina, uma história inacabada. Rio de Janeiro: Fiocruz. 470p

BESERRAL EB, FREITAS EM, SOUZALL JT, FERNANDES CRM, SANTOS KD. 2009. Ciclo de Vida de Aedes (Stegomyia) aegypti (Diptera, Culicidae) em águas com diferentes características. . Iheringia Sér. Zool. 99: 281-285.

BRASIL. MINISTÉRIO DA SAÚDE. Secretaria de Vigilância de Saúde. Departamento de Vigilância Epidemiológica. Doenças infecciosas e parasitarias: guia de bolso I Ministério da Saúde, Secretaria de Vigilância em saúde, departamento de vigilância epidemiológica. -8.ed. ver. -Brasília: Ministério da Saúde, 2010. 448 p. :II - (série B. textos básicos de saúde). pp.177 -181 .

CAVALCANTE KRLJ, TAUIL PL. 2014. Características epidemiológicas da febre amarela no Brasil no período de 2000 a 2012. 25: 11-20

CONSOLI RAGB, OLIVEIRA RL. 2016. Principais mosquitos de importância sanitária no Brasil. Rio de Janeiro: FioCruz. 228pp.

COSTA ZGA, ROMANO APM, ELKHOURY ANM, FLANNERY B. 2011. Evolução Histórica da Vigilâcia Epidemiollógica e do Controle da Febre Amarela no Brasil. n.1. Rev Pan-Amaz Saúde. v.2.

FORATTINI OP. 2002. Culicidologia médica: identificação, biologia e epidemiologia. EDUSP. 864pp.

FRAGA C. 1930. A Febre Amarela no Brasil: notas e documentos de uma grande campanha sanitária. Rio de Janeiro: Off. Graph. da Insp. de Demographia Sanitaria. 361pp.

FRANCO O.1969. História da Febre Amarela no Brasil. Editora Fiocruz. Volume 1. 212pp. pp. 5-8.

HERVÉ JPN, DEGALLIER APA. 1985. A Febre Amarela Silvestre no Brasil e os Riscos de Propagação Urbana. Hiléia Médica. pp. 31-40.

LEMOS M. 2015. Coleção Estudo - Biologia. Bernoulli. Vol.1.pp.46

MINISTÉRIO DA SAÚDE. SECRETARIA DE VIGILÂNCIA EM SAÚDE. Departamento de Vigilância Epidemiológica. Diretrizes nacionais para a prevenção e controle de epidemias. Brasília: Ministério da Saúde; 2017. (Série A. Normas e Manuais Técnicos.) 
NOBRE A, ANTEZANA D, TAUIL PL. 1994. Febre Amarela e Dengue no Brasil: Epidemiologia e Controle. Rev Soc Bras Med Trop. pp.59-66.

REZENDE JM. 2009. O Desafio da Febre Amarela. UNIFESP. A Sombra do Plátano. 407pp.

ROMANO APM, RAMOS DG, ARAÚJO FAA, SIQUEIRA GAM, RIBEIRO MPD, LEAL SG, et al. 2011. Febre Amarela no Brasil: Recomendações para Vigilância, Prevenção e Controle. Epidemiol. Serv. Saúde. pp 101-106.

SENISE E, SENISE MH. 2011. História Fundamental $9^{\circ}$ ano. Atual. 352pp.

SESA-ES - Secretaria de Estado da Saúde do Espírito Santo- 2017.

SILVA JR. 1930. A Febre Amarela no Brasil: Notas e Documentos de Uma Grande Campanha Sanitária. Rio de Janeiro: Off. Graph. da Insp. de Demographia Sanitaria. pp.69-80.

SINGER P, CAMPOS O, OLIVEIRA E M. 1988. Prevenir e Curar: O Controle Social Através dos Serviços de Saúde. $3^{\mathrm{a}} \mathrm{ed}$. Rio de Janeiro Forense Universitária. 7pp.

SUVISA - Superintendência de Vigilância em saúde - governo de Goiás. 2017.

VASCONCELOS PFC. 2002. Febre Amarela: Reflexões Sobre a Doença, as Perspectivas para o Século XXI e o Risco da Reurbanização. n.2. Rev. Bras. Epidemiol. Vol.5. 258pp.

VASCONCELOS PFC. 2003. Febre Amarela. Revista da Sociedade Brasileira de Medicina Tropical. 293pp.

VASCONCELOS PFC. 2010. Febre Amarela no Brasil: Pensamentos e Hipóteses Sobre o Surgimento em Áreas Anteriormente Livres. n.6. Rev. Saúde Pública. 44: 275-293

WERMELINGER ED,CARVALHO RW. Métodos e procedimentos usados no controle do Aedes aegypti na bem-sucedida campanha de profilaxia da febre amarela de 1928 e 1929 no Rio de Janeiro. Epidemiol. Serv. Saúde. pp. 837-844, 2016.

ZARA ALSA, SANTOS SM, OLIVEIRA ESF, Carvalho RB, Coelho GE. Estratégias de Controle do Aedes aegypti: Uma Revisão. 2aed. Epidemiol. Serv. Saúde. 25: 391-404, 2016.

\section{Como citar este artigo (Formato ABNT):}

COSTA, Raissa de Moura; FACIOLI; Larissa de Souza; REIS, Thainá Desiree Franco dos; SÁ, Odila Rigolin de; BERNARDES, Nicole Blanco. Febre Amarela: Sua Perspectiva No Brasil. Id on Line Rev.Mult. Psic., 2018, vol.12, n.41, p.435-448. ISSN: 1981-1179.

Recebido: $15 / 06 / 2018$

Aceito 27/06/2018 